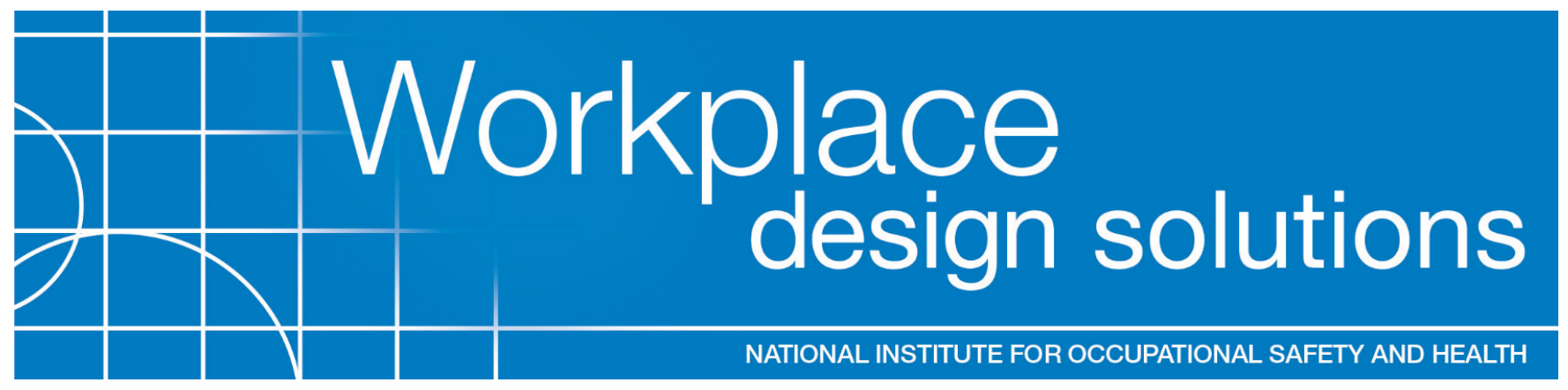

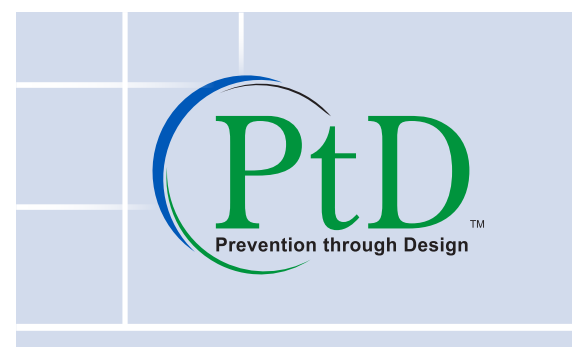

\section{Prevention through Design (PtD)}

Prevention through Design (PtD) can be defined as designing out or eliminating safety and health hazards associated with processes, structures, equipment, tools, or work organization. The National Institute for Occupational Safety and Health (NIOSH) launched a PtD initiative in 2007. The mission is to reduce or prevent occupational injuries, illnesses, and fatalities by considering hazard prevention in the design, re-design, and retrofit of new and existing workplaces, tools, equipment, and work processes [NIOSH 2008a,b].

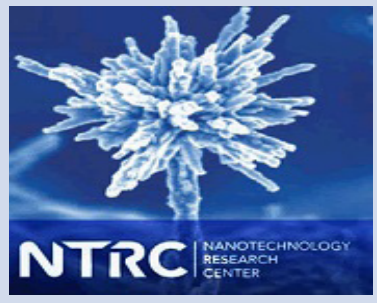

ENGINEERING CONTROL

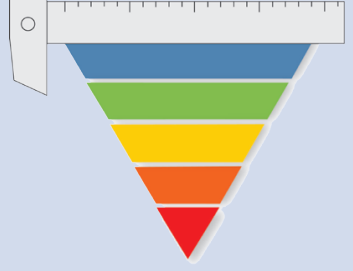

Protecting Workers during Intermediate and Downstream Processing of Nanomaterials

\section{Summary}

Engineered nanomaterials (ENM) are materials that are intentionally produced to have at least one primary dimension less than 100 nanometers $(\mathrm{nm})$. These materials have new or unique properties different from those of larger forms of the same material, making them desirable for specific product applications. The health effects associated with nanomaterials are not yet clearly understood, so it is important for producers and users of ENMs to reduce employee exposure and manage risks appropriately. In 2013, NIOSH published a compendium of control approaches for nanomaterial production and use processes entitled Current Strategies for Engineering Controls in Nanomaterial Production and Downstream Handling Processes. This Workplace Design Solutions document provides guidance on exposure control approaches for intermediate and downstream processes commonly used after the production of nanomaterials.

\section{Background}

The toxicity of many nanomaterials is presently unknown, but initial research indicates that there may be health concerns related to occupational inhalation exposures. Only a few types of ENMs have undergone extensive toxicological evaluation by NIOSH, e.g., titanium dioxide $\left(\mathrm{TiO}_{2}\right)$ and carbon nanotubes (CNTs). Results from animal studies with $\mathrm{TiO}_{2}$ and other poorly soluble, low toxicity particles of fine and ultrafine (nanoscale) sizes have shown adverse pulmonary responses in exposed rats, including persistent pulmonary inflammation and lung tumors [NIOSH 2011; Oberdörster 2002; Donaldson 2009; Poland et al. 2012]. Similar toxicological responses have also been observed in rats and mice exposed to CNTs and carbon nanofibers (CNFs) [NIOSH 2013a]. Because of the potential for health effects, it is important to control worker exposure and to manage risks appropriately throughout the lifecycle of ENM production.

\section{Description of Exposure}

After production, many nanomaterials are further processed. Ding et al. [2016] reviewed the published literature of nanomaterial release during various industrial and laboratory processes. They found that the amount and type of nanomaterial released into the workplace was largely based on the process energy. 
High energy processes, including spraying and machining (e.g., ball milling), were found to release nanoparticles. However, low energy processes, such as packing and bagging of nanomaterials during downstream processing tended to release relatively large agglomerates of nanomaterials into the workplace.

$\mathrm{NIOSH}$ recommends that manufacturers and downstream users of nanomaterials develop Prevention through Design strategies to protect workers (including maintenance personnel) during the production and handling of engineered nanomaterials. Engineering controls protect workers by controlling the source of hazardous materials or isolating the worker from the hazard, and along with good work practices, are likely to be the most effective control strategy for nanomaterials. Traditionally, a hierarchy of controls (represented as an upside down triangle) has been used as a means of determining the preferred types of feasible and effective controls. The idea behind the hierarchy of controls is that the control methods at the top of the triangle (elimination, substitution, and engineering controls) are generally more effective in reducing the risk associated with a hazard than those at the bottom (administrative controls and personal protective

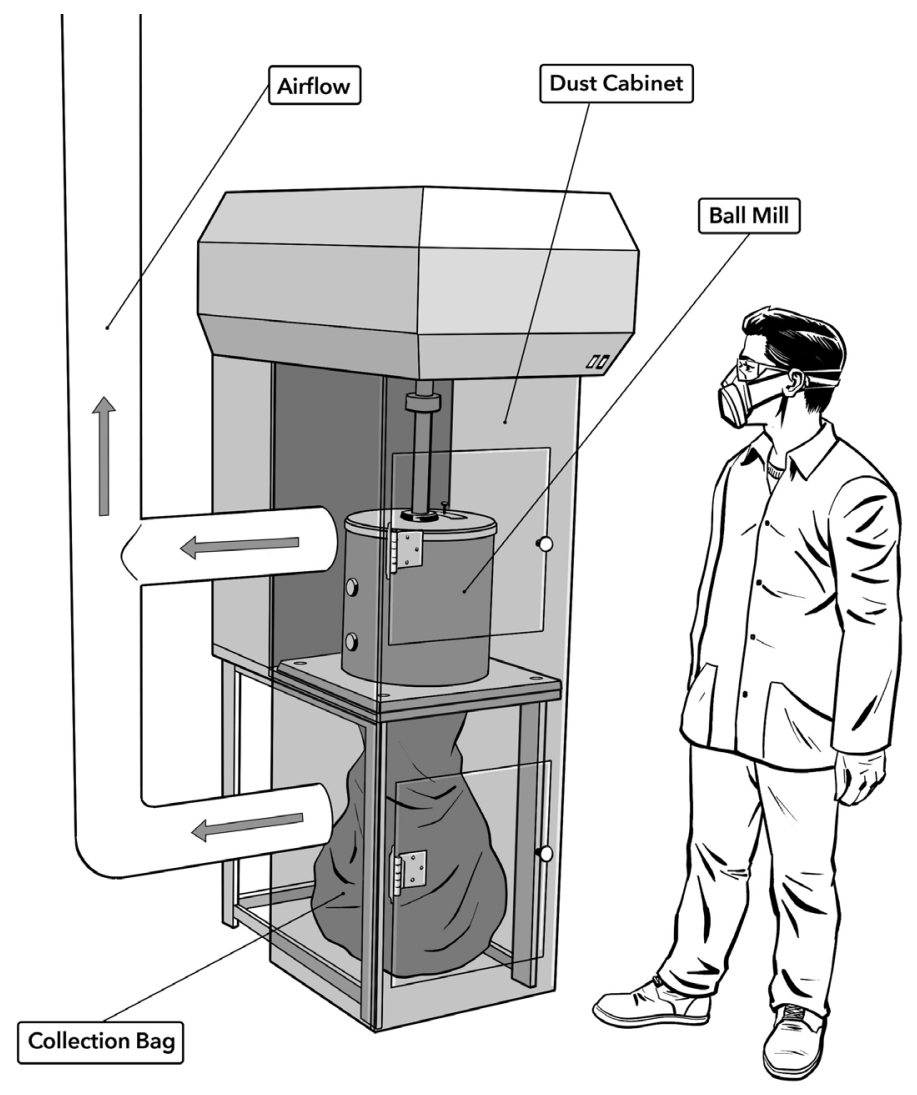

equipment). The identification and adoption of effective engineering control technologies is an important first step in reducing the risk associated with worker exposure to ENMs.

\section{Engineering Controls}

A qualified industrial hygienist can help assess process-related risks and make recommendations to minimize exposure. Control measures for ENMs and other hazards should be implemented within the context of a comprehensive occupational safety and health management system [ANSI/AIHA 2012]. Engineering controls used during post-production processing of nanomaterials may include local exhaust ventilation (LEV) such as annular exhaust hoods, enclosures around the emission points, or even down flow booths for larger scale processes. Each of these controls should be carefully designed for the process, tested, and properly operated to be effective. Below is a description of exposure sources (i.e., points of potential release of ENMs during processing) and control approaches for a range of common processes used with nanomaterials.

\section{Ball Milling}

Ball milling machines may be used to reduce particle size, mix or blend materials, or change particle shape. Workers may be exposed to nanomaterials during this process primarily when loading or unloading materials into the ball mills. Witschger et al. [2007] investigated aerosol emissions during the high energy ball milling process. They concluded that an aerosol was released when handling ENMs before and after the milling process. To contain potential emissions, smaller ball mills may be placed in ventilated enclosures, such as dust cabinets, to reduce worker exposure to nanomaterials. Larger ball mills may require the use of a specially designed enclosure.

\section{Ball Mill Enclosure}

- Ventilated enclosure for capturing emissions during the processing of nanomaterials in a larger ball mill. Use see-through panels to allow for visibility.

- Design must account for access needs. Include hinged doors for allowing loading and unloading of the mill.

- Consider sealing the collection bag before removal from the enclosure to reduce the likelihood of spills and unintentional release of ENMs.

- Wet wipe the outside of the bag before removing it from the enclosure to minimize spread of material. 


\section{Spray Dryer}

Following completion of production, nanomaterials may be refined through a common process such as spray drying [Lindeløv and Wahlberg 2009]. In the spray-drying process, a mixture of liquid and powder ingredients (slurry) is sprayed within a large sealed tank. Heat within the tank dries the slurry droplets, leaving a powder as the finished product. When the process is completed, the powder nanomaterial is commonly discharged into a drum or other container before packaging. Methner et al. [2010] reported exposure measurements at 12 facilities and noted that the highest background-adjusted concentration was observed during spray dryer drum change out. Evans et al. [2010] reported exposures related to changing out a drum that collected fugitive carbon nanofiber materials from a process reactor using a baghouse filtration system. These drums are often connected to the process outlet (thus minimizing exposure during operation), but workers may be exposed when removing/replacing the drums. The use of an annular hood, along with isolation valves and clamps to better contain potential emissions, can help reduce exposures.

\section{Spray Dryer Product Collection Hood}

- Local exhaust ventilation can be used to capture emissions during the collection of a product processed in a spray dryer.

- Place the exhaust pickup as close to the emission source as possible. The exhaust hood capture air velocity (speed) at the point where particles may be released should usually be at least 100 feet per minute (fpm).

- Use baffles and shields to enclose the process as much as possible. Cross currents and drafts in the workplace can significantly reduce particle capture effectiveness.

- Note the use of an isolation valve to manually shut off the flow of material after the drum is filled and being removed.

- Note that a clamp can be used to create a dust-tight seal on the discharge outlet of the spray dryer during normal operation.

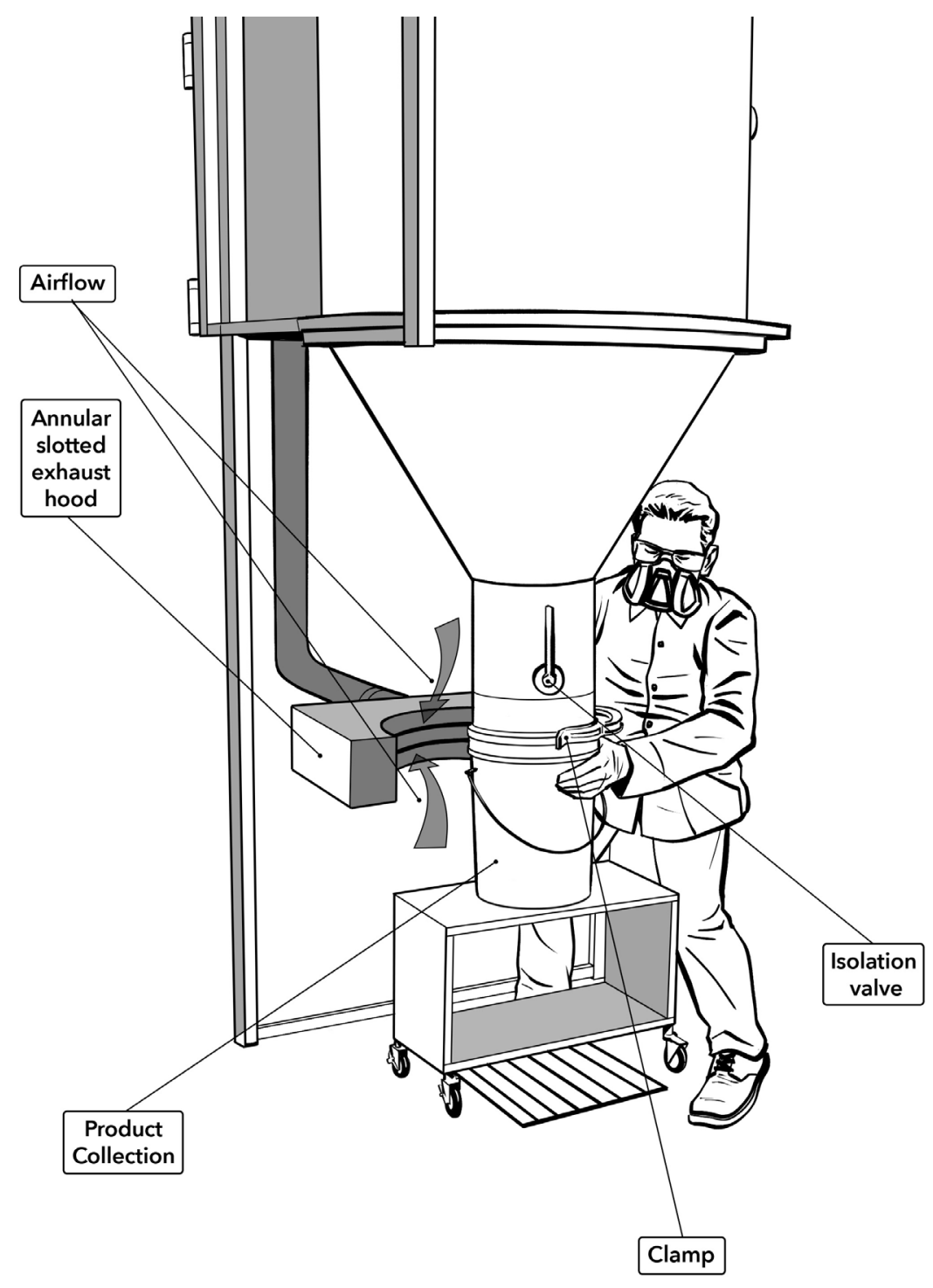




\section{Extrusion}

The addition of ENM to a thermoplastic using an extrusion process to create a nanocomposite with improved properties may also present the potential for worker exposure. This process starts by adding a nanomaterial into a hopper where it is fed into the barrel of the extruder. This nanomaterial may be added as the nanoparticles in powder form or as part of a masterbatch. The mixture is gradually melted by heaters arranged along the barrel and the mechanical energy generated by turning screws. The molten polymer is then forced through a die and cooled in a bath before being spooled or chopped into small pieces. Researchers have shown that individual and agglomerated nanoparticles from the feed/filler nanomaterial as well as polymer fume condensate can be emitted into the workplace during the extrusion process [Thompson et al. 2015; Tsai et al. 2008a]. Tsai et al. [2008b] showed that enclosing and ventilating potential nanoparticle release points can result in substantial reductions in process emissions.

\section{Extruder Hood and LEV System}

- Consider using an exhaust hood and LEV system to capture emissions during the loading of nanomaterials/fillers and during nanocomposite discharge from the extruder.

- The hood should be shaped to enclose the source as much as possible while allowing access during operations.

- Place the exhaust pickup of the LEV as close to the emission source as possible. The exhaust hood capture air velocity (speed) at the point where contaminants are released should usually be at least $100 \mathrm{fpm}$.

- When clearing clogged extruder heads, consider cleaning the head inside a ventilated enclosure to minimize the potential for worker exposure, especially when using a torch.

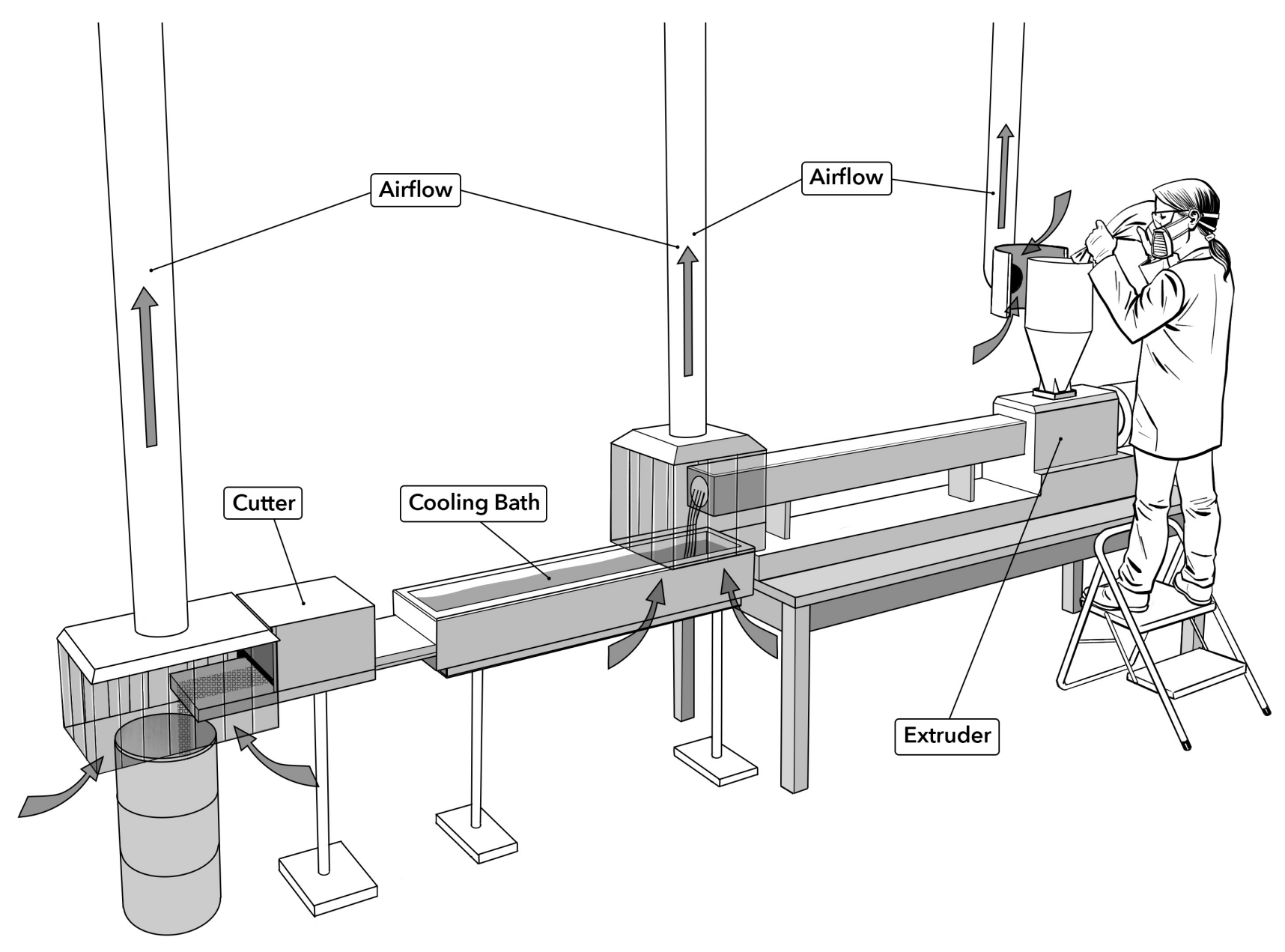




\section{Product Discharge/Bag Filling}

The process of filling or emptying bags/drums with nanomaterials is done following production or refining processes. The off-loading of product after spray drying, for example, may be a significant source of exposure when post-processing nanomaterials. Evans et al. [2010] studied nanoparticle concentrations in a facility that manufactured and processed carbon nanofibers (CNFs). The largest increases in particle concentration (consisting of mostly aerosolized CNFs) measured within the plant were related to the dumping of product into lined drums and manual change-out and closing of bags of the final treated product. A method that can be used to contain powders during process off-loading/emptying is the continuous liner system. Polypropylene liners are often used when products are discharged from the industrial processes into the intermediate or final product containers.

\section{Continuous Liner for Product Collection}

- Consider using a continuous liner product off-loading system that contains process emissions and product with a continuous feed of bags fitted to the process outlet.

- In this operation, a sleeve of polypropylene (poly) liners is stowed around the circumference of the discharge outlet. The liner (the bottom having been sealed) is pulled down into the overpack (usually a drum or a cardboard box). An outer liner may also be used to provide additional product containment instead of a hard overpack.

- Product is discharged into the liner through an isolation valve on the process outlet. Once full, the top of the first liner sleeve is closed using tape or a fastener, or it is heat sealed and cut. The product is then sealed within the poly-lined container, and a new poly liner is pulled down and sealed before starting discharge into the next container.

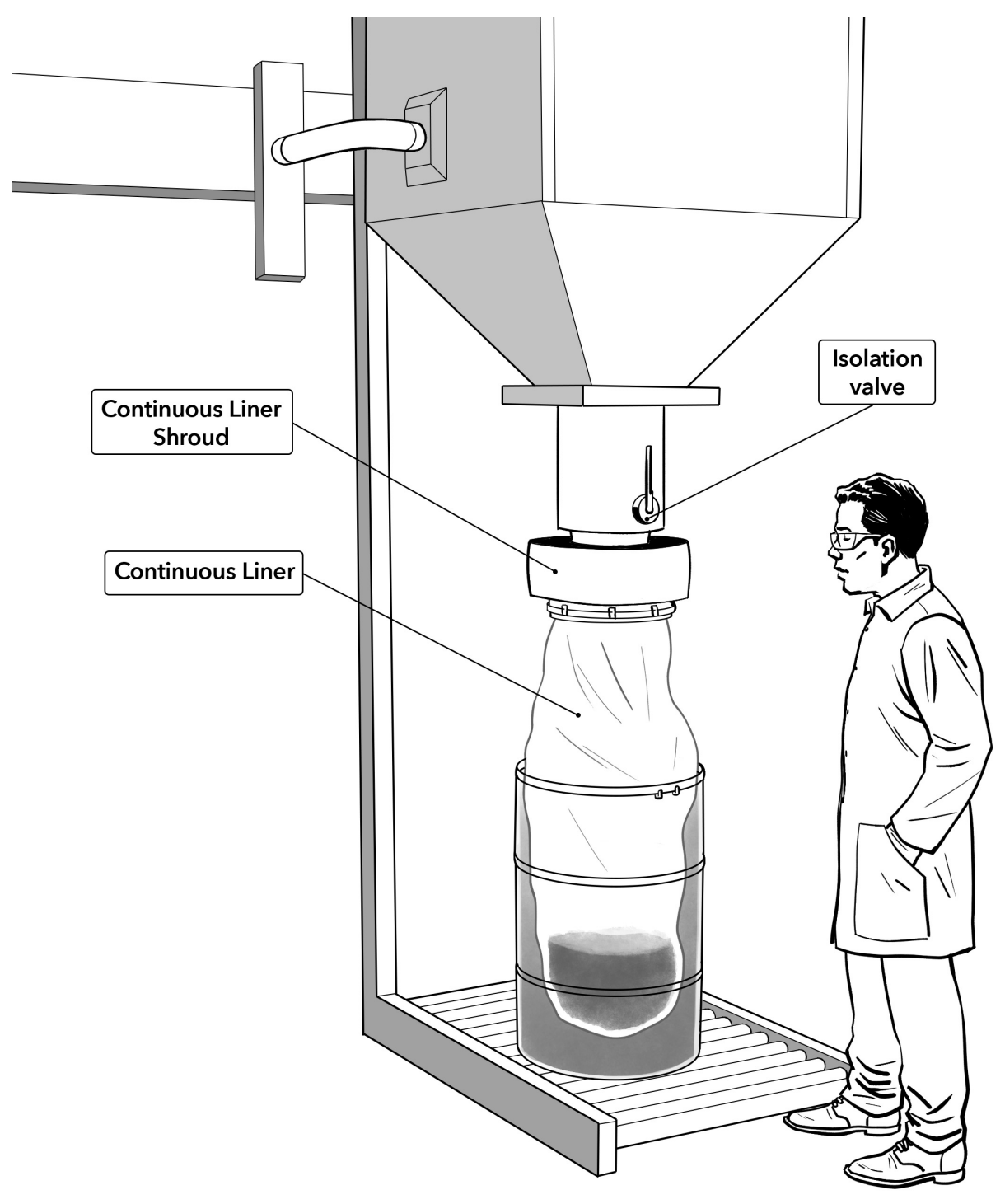




\section{Bag Dumping}

Bekker et al. [2015] conducted a study of occupational exposures in companies working with nanomaterials downstream of production (e.g., during use and application). They found that the highest measured concentrations were associated with larger scale/high energy tasks including spray activities and the dumping and mixing of powders. Technology for controlling dusts during bag dumping has been available for many years [NIOSH 2013b]. The standard controla ventilated bag dump station-consists of a hopper outfitted with an exhaust ventilation system to pull dust away from workers as they open and dump bags of powdered materials. This equipment can reduce the concentration of airborne dust caused by manually emptying bags or disposing of empty bags, but also relies on careful work practices.

\section{Ventilated Bag Dump Station}

- Use a ventilated bag dumping station to reduce dust emissions to the workplace air when emptying product from bags into a process hopper.

- Include a waste bag collection chute to allow for the disposal of bags following dumping.

- Enclose the system, including the waste bag collection area as much as possible.

- Ensure airflow into the enclosure between 100 -200 fpm.

- Locate the bag disposal point so that it can be easily reached and does not require the worker to place his/her head within the enclosed area.

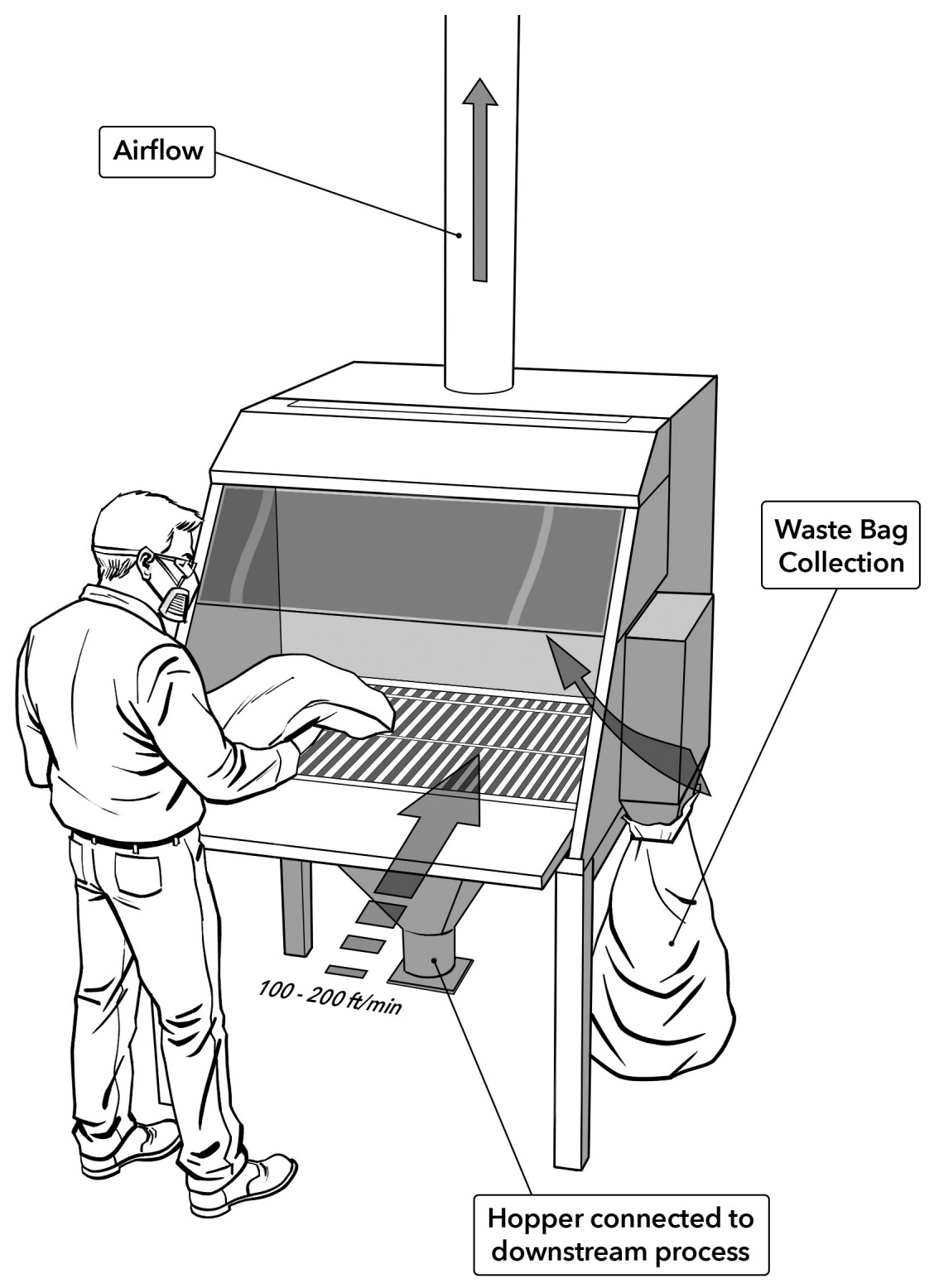




\section{Large-scale Material Handling/Packaging}

Unidirectional flow booths, or downflow booths, are used in the pharmaceutical industry for large-scale powder packaging, process loading, and tray dryer loading [Hirst et al. 2002]. In general, these booths supply air from overhead (normally at 80-100 fpm) over the full depth of the booth. Particles generated in the booth are captured and carried to exhaust registers located along the back wall of the booth. The booths provide flexibility for a variety of operations that require handling of nanomaterials from larger containers, such as drums. Floura and Kremer [2008] evaluated a downflow booth used for transferring 55 lbs of lactose (a surrogate pharmaceutical material) from drum to drum. The concentration within the operator's breathing zone averaged 2,250 $\mu \mathrm{g} / \mathrm{m}^{3}$ without any ventilation controls and was reduced to an average of $1.01 \mu \mathrm{g} / \mathrm{m}^{3}$ when the booth ventilation was turned on.

\section{Downflow Booth-Large Scale Material Handling}

- Consider using a downflow booth to contain nanomaterials and reduce exposure to a worker handling larger amounts of nanomaterial powders (such as drums/barrels).

- When air is recirculated into the booth, HEPA-filtered air is delivered through the ceiling-mounted supply air registers at a velocity of $80-100 \mathrm{fpm}$. This air is returned near the floor of the booth to draw any airborne powders away from the worker's breathing zone. Note these filters will not remove volatile chemicals/vapors and care must be taken when using them.

- These booths can be designed to incorporate LEV for additional exposure reduction for specific operations.

- When scooping powders from bulk containers, shorter drums and/or long handled scoops should be used to eliminate the need for the worker to put their heads inside the drum [NIOSH 1997].

- Downflow booths are available from several commercial vendors.

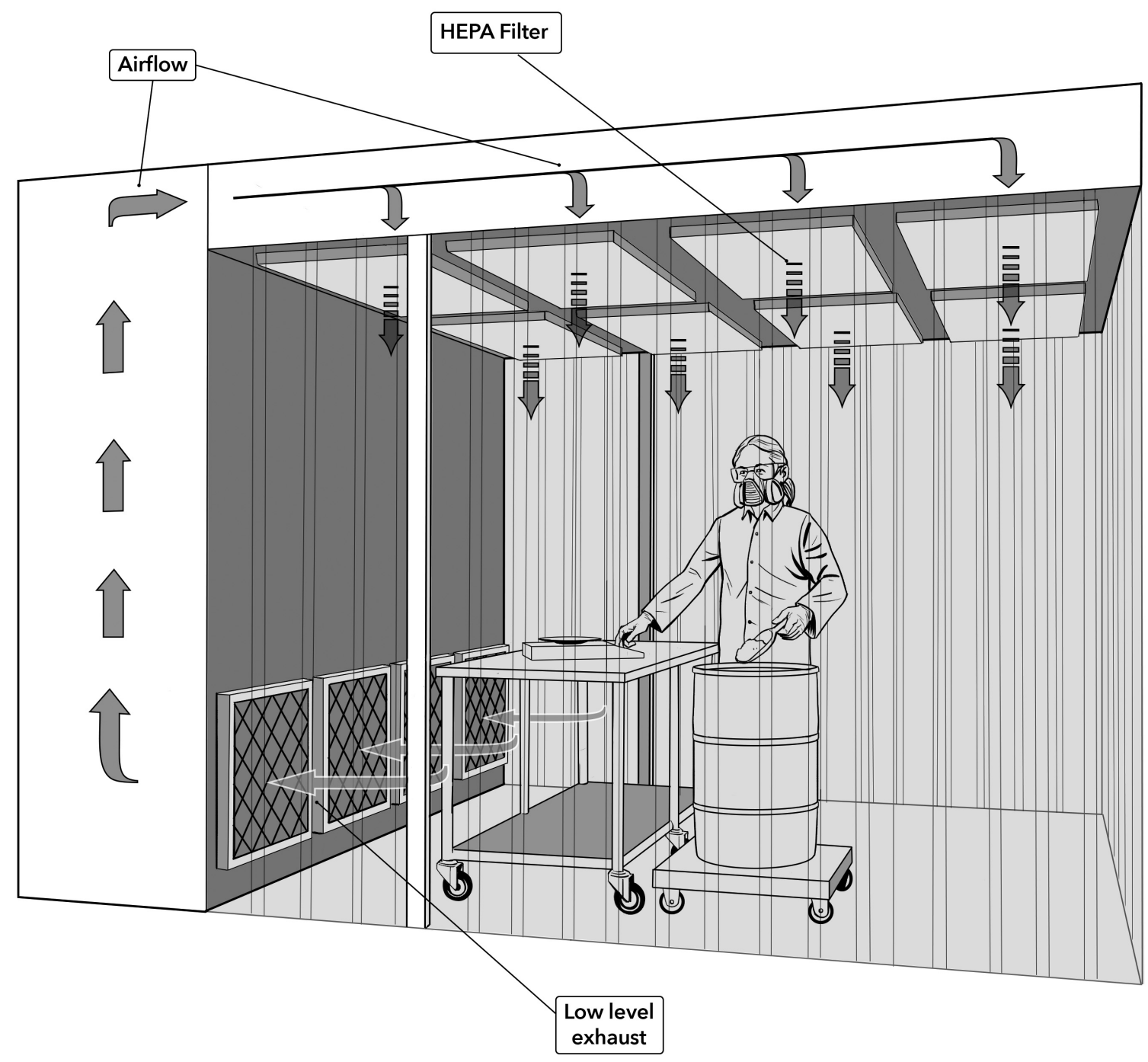




\section{Design and Operational Considerations}

The local exhaust ventilation hood or enclosure should be designed to effectively capture the nanomaterials inadvertently released from the process. It should be tailored to the specific process being controlled (especially important for hot processes and processes releasing materials into the air at high velocities). Information about the design, operation, and maintenance of engineering controls for industrial processes is available from a variety of sources [ACGIH 2007, 2016; Burton 1999; Burgess et al. 2004]. When designing these types of controls, it is necessary to take the following actions:

Consult a qualified industrial ventilation engineer, industrial hygienist, or containment specialist to design the new control system.

Consider access requirements when designing the control to ensure that the operator can perform required tasks without reducing control effectiveness (e.g., leaving enclosure doors open).

Determine exhaust airflows capable of maintaining a negative pressure (even during the opening of access doors). Fans that move air through the LEV system need to be adequately sized to ensure the system works properly.

Provide an easy way to check that the control system is working, e.g., manometer, pressure gauge or other visual indicator. Train workers to confirm that the control is turned on and working properly before use.

Discharge exhaust air to a safe place away from doors, windows, and supply air intakes in accordance with local and state regulations. Consider discharging exhaust through a high efficiency particulate air (HEPA) filter.

Keep exhaust ducts short and simple-avoid flexible duct if possible. The choice of duct material needs to be compatible with both the nanomaterials and other materials in the process.

Conduct initial performance tests of the control when it is installed at the facility. These tests should be scheduled as part of a regular preventive maintenance program to ensure adequate containment.

\section{Preventative Maintenance and System Checks}

Develop a written preventive maintenance (PM) plan to check system performance and repair.

$\square$ Keep equipment in effective and efficient working order. Review the manufacturer's performance specification to know whether the control is working properly.

$\square$ Look for signs of damage to the ducting and enclosure. Repair damage immediately.

$\square$ Regularly check that the enclosure/hood system is working properly and that there are no visible dust leaks.

$\square$ Have a qualified industrial ventilation engineer or industrial hygienist examine the ventilation control system and check its performance at least once every year or if it is modified or relocated.

Keep the information obtained from all engineering control system tests/checks in a PM logbook.
Conduct routine industrial hygiene monitoring to ensure controls are working at design conditions.

$\square$ To prevent potential exposures to maintenance personnel, potentially contaminated equipment should be cleaned or bagged and sealed before being removed from the production area.

\section{Administrative Controls}

The use of engineering controls is likely the most effective control strategy for nanomaterials. Administrative controls (e.g. work practices) and personal protective equipment (PPE) also have a place in $\mathrm{PtD}$ strategies and are usually identified as additional safeguards. Work practices are procedures followed by employers and workers to control hazards in the workplace. These practices, many of which are discussed below, include housekeeping and cleaning, storage and use procedures, labels and postings, hazard training, and procedures for the use of engineering controls. In addition, respirators may be needed and are often used during the implementation of engineering controls and work practices as well as during some short-duration maintenance procedures, and emergencies. Therefore, facilities should consider the following administrative and PPE approaches as a part of a comprehensive occupational safety and health management plan for nanomaterial production and use.

\section{Cleaning and Housekeeping}

Clean the work area and equipment every day. Deal with spills immediately according to written procedures and using appropriate PPE. Standard approaches for cleaning spills can be used for cleaning surfaces contaminated with dry powder nanomaterials. These include using HEPA-filtered vacuum cleaners, wiping up dry powders with damp cloths, or wetting the powder before wiping.

Dispose of cleaning wipes and other contaminated materials in a sealed bag to prevent release of the dried nanomaterial. Nanomaterial-contaminated waste, including cleaning materials, should be kept in a separate waste stream.

Do not use dry methods such as a brush, broom, or compressed air to clean up contaminated work surfaces. Care must be taken when using wet methods for housekeeping activities to make sure that any other safety hazards (e.g., electrical hazards, slips/trips, etc.) are not introduced into the workplace.

\section{Training}

Provide safety and health training to workers, supervisors, and managers including information on proper use, maintenance and inspection of the control.

Provide workers with sufficient information to allow them to understand the nature of potential workplace exposures, health risks, routes of exposure, and instructions for reporting health symptoms [OSHA 2012].

Ensure that training includes how to keep exposures low; how to check that the exposure control is working; how to use and care for PPE; how to use and care for respirators; and what to do if something goes wrong. 


\section{Personal Protective Equipment}

\section{Personal Protective Clothing}

Because some types of nanoparticles have been found to penetrate the skin under certain conditions, prudent practice calls for appropriate protective clothing to be worn. PPE should be worn when engineering and/or administrative controls are not feasible or effective in reducing exposures to an acceptable level, or when controls are not feasible, such as during maintenance or in response to a spill. Follow job hazard assessment procedures for determining the need for and selection of PPE [OSHA 2002; ACS 2015].

If appropriate, use nitrile or other chemically impervious gloves during handling and cleanup of nanomaterials. Gloves should be selected based on their effectiveness against the nanomaterial as well as any other chemicals being used. Gloves should be inspected before use and changed at least at the end of each shift and whenever they show visible signs of wear. Used gloves should be kept in a sealed plastic bag in the work area until they can be disposed of properly.

$\square$ Never use compressed air or other high energy techniques such as brushing or shaking to remove dust from clothing.

Protective clothing made from air tight polyethylene is more resistant to nanoparticle penetration than cotton or polyester [Woskie 2010].

\section{Respirators}

Employers should consult with an occupational safety and health professional to determine the respirator best suited for their specific application. In the U.S., employers should always follow the Occupational Safety and Health Administration (OSHA) Respiratory Protection Standard (29 CFR 1910.134) if respiratory protection is used (www.osha.gov/SLTC/etools/respiratory/index.html). $\mathrm{NIOSH}$ guidance for selecting respirators may be found at http:// www.cdc.gov/niosh/docs/2005-100/default.html [NIOSH 2004].

\section{Acknowledgments}

This document was prepared by Dr. Kevin H. Dunn, Ms. Jennifer Topmiller, and Ms. Trudi McCleery, NIOSH Division of Applied Research and Technology, and Mr. John J. Whalen, formerly with NIOSH. Mr. Eugene Smith (on contract with NIOSH) prepared the illustrations. The authors gratefully acknowledge the contributions of the following NIOSH personnel who assisted with the technical content and review of the document, including: Dr. Charles Geraci, Ms. Laura Hodson, Ms. Susan Afanuh, Dr. Samy Rengasamy, Mr. Kevin L. Dunn, Mr. Eric Glassford and Mr. Matthew Dahm. Special appreciation is expressed to the following who served as external reviewers, including Ms. Renae Goldman, Dr. Torey Nalbone, and Dr. Kevin Sheffield.

\section{Suggested Citation}

NIOSH [2018]. Protecting workers during Intermediate and downstream processing of nanomaterials. By Dunn KH, Topmiller JL, McCleery T, Whalen J. DHHS (NIOSH) Publication No. 2018122. DOI: https://doi.org/10.26616/NIOSHPUB2018122

\section{References}

ACGIH [2016]. Industrial ventilation: a manual of recommended practice for design. 29th ed. Cincinnati, OH: American Conference of Governmental Industrial Hygienists.

ACGIH [2007]. Industrial ventilation: a manual of recommended practice for operation and maintenance. Cincinnati, $\mathrm{OH}$ : American Conference of Governmental Industrial Hygienists.

ACS [2015]. Identifying and evaluating hazards in research laboratories. Washington, DC: America Chemical Society. https:// www.acs.org/content/dam/acsorg/about/governance/committees/chemicalsafety/publications/identifying-and-evaluatinghazards-in-research-laboratories.pdf.

ANSI/AIHA [2012]. Occupational health and safety management systems. Fairfax, VA: American Industrial Hygiene Association Publication No. ANSI Z10-2012.

Bekker C, Kuijpers E, Brouwer DH, Vermeulen R, Fransman $\mathrm{W}$ [2015] Occupational exposure to nano-objects and their agglomerates and aggregates across various life cycle stages; a broad-scale exposure study. Ann Occup Hyg 59(6):681-704.

Burgess WA, Ellenbecker MJ, Treitman RD [2004]. Ventilation for the control of the work environment, $2^{\text {nd }}$ ed. Hoboken, NJ: John Wiley \& Sons, Inc.

Burton DJ, ed [1999] Hemeon's plant and process ventilation, 3rd ed. Boca Raton, Fla.: Lewis Publishers.

Ding Y, Kuhlbusch TAJ, Van Tongeren M, Jimenez AR, Tuinman I, Chen R, Alvarez IL, Mikolajczyk U, Nickel C, Meyer J, Kaminski H, Wohlleben W, Stahlmecke B, Clavaguera S, Riediker M [2016]. Airborne engineered nanomaterials in the workplace-a review of release and worker exposure during nanomaterial production and handling processes. J Haz Mat 322(Part A):17-28. http://dx.doi.org/10.1016/j.jhazmat.2016.04.075.

Donaldson K [2009]. The inhalation toxicology of p-aramid fibrils. Crit Rev Toxicol 39:487-500.

Evans DE, Ku BK, Birch ME, Dunn KH [2010]. Aerosol monitoring during carbon nanofiber production: mobile direct-reading sampling. Ann Occup Hyg 54(5):514-531.

Floura H, Kremer J [2008]. Performance verification of a downflow booth via surrogate testing. Pharmaceut Eng 28(6):1-9.

Hirst N, Brocklebank M, Ryder M [2002]. Containment systems: a design guide. Woburn, MA: Gulf Professional Publishing, p. 199.

Lindeløv JS, Wahlberg M [2009]. Spray drying for processing of nanomaterials. J Phys: Conference Series 170(1).

Methner M, Hodson L, Dames A, Geraci C [2010]. Nanoparticle emission assessment technique (NEAT) for the identification and measurement of potential inhalation exposure to engineered nanomaterials_-part B: results from 12 field studies. J Occup Environ Hyg 7(3):163-176.

NIOSH [1997]. Hazard controls: control of dust from powder dye handling operations. DHHS (NIOSH) Publication No. 97-107. https://www.cdc.gov/niosh/docs/hazardcontrol/hc13.html.

NIOSH [2004]. NIOSH respirator selection logic 2004. By Bollinger N. DHHS (NIOSH) Publication No. 2005-100. https:// www.cdc.gov/niosh/docs/2005-100/default.html. 
NIOSH [2008a]. Prevention through design: introduction. By Howard J. J Safety Res 39:113. http://www.cdc.gov/niosh/topics/ ptd/pdfs/Howard.pdf.

NIOSH [2008b]. National prevention through design (PtD) initiative. By Schulte P, Rinehart R, Okun A, Geraci C, Heidel D. http://www.cdc.gov/niosh/topics/ptd/pdfs/Schulte.pdf.

NIOSH [2011]. Current intelligence bulletin 63: occupational exposure to titanium dioxide. DHHS (NIOSH) Publication No. 2011-160. http://www.cdc.gov/niosh/docs/2011-160/.

NIOSH [2013a]. Current intelligence bulletin 65: occupational exposure to carbon nanotubes and nanofibers. DHHS (NIOSH) Publication No. 2013-145. http://www.cdc.gov/niosh/docs/2013-145/.

NIOSH [2013b]. Current strategies for engineering controls in nanomaterial production and downstream handling processes. DHHS (NIOSH) Publication No. 2014-102. https://www.cdc. gov/niosh/docs/2014-102/pdfs/2014-102.pdf.

Oberdörster G [2002]. Toxicokinetics and effects of fibrous and nonfibrous particles. Inhal Toxicol 14:29-56.

OSHA [2002]. Job hazard analysis. U.S. DOL (OSHA) Publication No. 3071 (Revised). https://www.osha.gov/Publications/osha3071.pdf.

OSHA [2012]. Hazard Communication (29 CFR 1910.1200). Retrieved from https://www.osha.gov/pls/oshaweb/owadisp. show_document?p_table=standards\&p_id=10099.
Poland CA, Byrne F, Cho W, Prna-Mello A, Murphy FA, Davies GL, Coey J, Gounko Y, Duffin R, Volkov Y [2012]. Lengthdependent pathogenic effects of nickel nanowires in the lungs and the peritoneal cavity. Nanotoxicol 6:899-911.

Thompson D, Chen S-C, Wang J, Pui DY [2015] Aerosol emission monitoring and assessment of potential exposure to multi-walled carbon nanotubes in the manufacture of polymer nanocomposites. Ann Occup Hyg 59(9):1135-1151.

Tsai SJ, Ashter A, Ada E, Mead J, Barry C, Ellenbecker MJ [2008a]. Airborne nanoparticle release associated with the compounding of nanocomposites using nanoalumina as fillers. Aerosol Air Qual Res 8(2):160-177.

Tsai SJ, Ashter A, Ada E, Mead J, Barry C, Ellenbecker MJ [2008b] Control of airborne nanoparticle release during compounding of polymer nanocomposites. Nano 3(4):301-309.

Witschger O, Wrobel R, Gaffet E and Coste S [2007]. Evaluation of aerosol release during high-energy ball milling of metallic oxide powders. 3rd International Symposium on Nanotechnology, Occupational and Environmental Health, Taipei, Taiwan: August 29-Sep. 1, 66-67.

Woskie S [2010]. Workplace practices for engineered nanomaterial manufacturers. WIREs Nanomed Nanobiotech 2(6):685-692.

\section{Information}

The information in this document is based on research related to Prevention through Design (PtD) initiatives. More information about $\mathrm{PtD}$ is available on the NIOSH Web site at http://www.cdc.gov/niosh/topics/PtD/

Detailed information about developing comprehensive PtD strategies for nanomaterial use and production has been developed by NIOSH [2013b] in the document Current Strategies for Engineering Controls in Nanomaterial Production and Downstream Handling Processes (http://www.cdc.gov/niosh/ docs/2014-102/pdfs/2014-102.pdf).

Telephone: 1-800-CDC-INFO (1-800-232-4636)

TTY: 1-888-232-6348 • CDC INFO: www.cdc.gov/info or visit the NIOSH website at www.cdc.gov/niosh

For a monthly update on news at NIOSH, subscribe to NIOSH eNews by visiting www.cdc.gov/niosh/eNews.
Mention of any company or product does not constitute endorsement by NIOSH. In addition, citations to Web sites external to NIOSH do not constitute NIOSH endorsement of the sponsing organizations or their programs or products. Furthermore, NIOSH is not responsible for the content of these websites.

This document is in the public domain and may be freely copied or reprinted. NIOSH encourages all readers of the Workplace Design Solutions to make them available to all interested employers and workers.

As part of the Centers for Disease Control and Prevention, $\mathrm{NIOSH}$ is the Federal agency responsible for conducting research and making recommendations to prevent workrelated illness and injuries. 